\title{
Mass Transfer and Extraction of Zinc from Rinse Water of Zinc Phosphate Coating via A Hollow Fiber Supported Liquid Membrane
}

\author{
Krittiya Wisutthisaen $^{\mathrm{a} *}$, Pharannalak Wannachod ${ }^{\mathrm{a}}$, Ura Pancharoen ${ }^{\mathrm{a}}$ \\ ${ }^{a}$ Department of Chemical Engineering, Faculty of Engineering, Chulalongkorn University, Bangkok 10330, \\ Thailand
}

\begin{abstract}
The extraction of $\mathrm{Zn}(\mathrm{II})$ ions from phosphating rinsing waters in automotive assembly process was investigated though a hollow fiber supported liquid membrane (HFSLM) by using di(2-ethyhylhexyl) phosphoric acid (D2EHPA) as a highly selective carrier for the transfer of zinc ions which diluted in kerosene and sulfuric acid solution have been used as the stripping solution. The various chemical parameters, such as the $\mathrm{pH}$ of the initial feed solution, the concentration of carrier, the concentration of stripping solution, the flow rate of feed and stripping solution were investigated. The optimum condition have been determined. The extraction of $\mathrm{Zn}$ (II) from feed phase was achieved at $91 \%$ by $8 \%(\mathrm{v} / \mathrm{v})$ or 0.25 molar of D2EHPA. Mass transfer modeling in the system was developed to predict the extent of $\mathrm{Zn}$ (II) extraction at different time. Extraction equilibrium constant $\left(K_{e x}\right)$, distribution ratio $(D)$, permeability $(P)$ and mass transfer were determined. The aqueous-phase mass-transfer coefficient $\left(K_{i}\right)$ and organic-phase mass-transfer coefficient $\left(K_{m}\right)$ were calculated.
\end{abstract}

Keywords: Zinc(II), Phosphating rinsing water, HFSLM, D2EHPA.

\subsection{INTRODUCTION}

Zinc is one of toxic heavy metals which have an important role for living things' growth [1], and it has widely been utilized in industry. Industrial waste water mingling with zinc is now causing problem to environment and human hygiene [2]. Since zinc is not biodegradable by natural processes [3]; moreover, it can be absorbed by plants [4]. Therefore, zinc has become links of food chain resulting in accumulating in human bodies, and has caused health problem e.g. signals of nervous systems, brain goes numb, vomiting, nausea, and anemia if obtaining too much amount of this.

In automotive industry, zinc has been used a lot in coating the metals before the painting work in order to enhance the resistance to corrosion.

"Corresponding author: Email: krittiya_wis@hotmail.com
This process is called "Zinc Phosphate Coating". The waste water from this process comes from the rinsing stage to wash away the remaining chemicals on the surface of the metals, to help stop the reaction, and to control the quality of the products. There must be a transfusion or overflowing the rinsing water all the time. The rinsing water contains $\mathrm{Zn}$ (II), $\mathrm{Ni}$ (II) and $\mathrm{Mn}$ (II) dissolving in the phosphoric acid solution, which has more amount of $\mathrm{Zn}$ (II) than the specification of The Industrial Thai Standard - as shown in Table 1.

From the previous researches, there have been many methods of rinsing water treatments which have many different purposes - as in Table 2. This researches focuses on analyzing zinc ions phosphoric acid solution to the form of sulfuric acid solution instead in order to bring the obtaining of the zinc sulfate to be used in the zinc plating process, so the process has been selected 
Table 1 Chemical composition of the rinsing water effluent

\begin{tabular}{lcc}
\hline Species & $\begin{array}{c}\text { Concentration of } \\
\text { rinsing water } \\
\text { effluent }(\mathbf{m g} / \mathbf{l})\end{array}$ & $\begin{array}{c}\text { Limit by } \\
\text { legislation. } \\
\text { (mg/l) }\end{array}$ \\
\hline $\mathrm{Zn}^{2+}$ & $15.0-20.0$ & $\leq 5$ \\
$\mathrm{Ni}^{2+}$ & $0.5-1.0$ & $\leq 1$ \\
$\mathrm{Mn}^{2+}$ & $0.5-1.0$ & $\leq 5$ \\
$\mathrm{PO}_{4}{ }^{3-}$ & 3578 & - \\
\hline
\end{tabular}

Table 2 Literature and citations for rinsing water treatment

\begin{tabular}{llll}
\hline \multicolumn{1}{c}{ Author } & \multicolumn{1}{c}{ Method } & \multicolumn{1}{c}{ Purpose } & Ref \\
\hline $\begin{array}{l}\text { S.Micheal } \\
\text { et al. }\end{array}$ & $\begin{array}{l}\text { Liquid-phase } \\
\text { polymer- } \\
\text { based } \\
\text { retention }\end{array}$ & $\begin{array}{l}\text { Recovery } \\
\text { phosphoric acid } \\
\text { solution }\end{array}$ & {$[5]$} \\
M.Kobya & $\begin{array}{l}\text { Electro- } \\
\text { coagulation }\end{array}$ & $\begin{array}{l}\text { Recovery } \\
\text { phosphoric acid } \\
\text { solution and } \\
\text { extraction of }\end{array}$ & {$[6]$} \\
& & $\begin{array}{l}\text { zinc ions } \\
\text { This work }\end{array}$ & \\
& $\begin{array}{l}\text { Hollow fiber } \\
\text { supported } \\
\text { liquid }\end{array}$ & $\begin{array}{l}\text { Extraction of } \\
\text { zinc ions from } \\
\text { phosphoric } \\
\text { membrane }\end{array}$ & $\begin{array}{l}\text { acid solution } \\
\text { to sulfuric acid } \\
\text { solution for } \\
\text { applied to zinc } \\
\text { plating process. }\end{array}$ \\
\hline
\end{tabular}

to be used in the research in order to analyze metal ions through a hollow fiber supported liquid member and because it is a most efficient technique for a low concentration [7]. Moreover it can be increased a concentration at strip phase. Selecting a proper extractant is important to the system. From the many previous researches have found that D2EHPA is a proper extractant in order to extract zinc from thesolution, which is acidity. The mentioned extractant is dissolved in kerosene which is a cheap and less dangerous solvent and has widely been used in industry.

This research presents the analysis of $\mathrm{Zn}$ (II) as dissolved on phosphoric acid solution through a hollow fiber supported liquid membrane using D2EHPA/kerosene as an extractant, and using sulfuric acid as a stripping solution. The experiment system is a semi batch type. There are reports of factor results which effects to the extraction in order to produce the most efficient extraction and the most outcomes and a trend towards an expansion of industrial section.

\subsection{THEORETICAL}

Extraction method though a liquid membrane is mass transfer across two opposite sides of its by permeation of the species proceeded due to a chemical potential gradient or the driving force [8] as continually reaction and completed in one step. The extractant is adsorbed into a micropore of the liquid membrane which made from hydrophobic material. The transport mechanism of the metal ions as in Figure 1.

The percentage of extraction and recovery was calculated by

$$
\begin{gathered}
\% \text { Extraction }=\frac{C_{f, \text { in }}-C_{f, \text { out }}}{C_{f, \text { in }}} \times 100 \\
\text { \% Stripping }=\frac{C_{f, \text { out }}}{C_{f, \text { in }}} \times 100
\end{gathered}
$$

The chemical extraction reaction is described [9] as

$$
\begin{aligned}
& \mathrm{Zn}_{(a q)}^{2+}+1.5(\mathrm{RH})_{2(\mathrm{org})} \\
& =\mathrm{ZnR}_{2} \mathrm{RH}_{(\mathrm{org})}+2 \mathrm{H}^{+}{ }_{(a q)}
\end{aligned}
$$

From the ion-extraction described in Eq.(3), the extraction equilibrium $\left(K_{e x}\right)$ can be expressed as

$$
K_{\text {ex }}=\frac{\left[\mathrm{ZnR}_{2} R H\right]_{\text {org }}\left[H^{+}\right]^{2}}{\left[\mathrm{Zn}^{2+}\right]\left[(\mathrm{RH})_{2(\mathrm{org})}\right]^{1.5}}
$$

The distribution ratio for zinc $(D)$ is given by

$$
D=\frac{\left[Z n R_{2} R H\right]_{\text {org }}}{\left[Z n^{2+}\right]}=\frac{\left.K_{e x}[(R H)]_{2, \text { org }}\right]^{1.5}}{\left[H^{+}\right]^{2}}
$$

The permeation of zinc can be expressed in terms of the permeability coefficient $(P)$ as proposed by Danesi [10] in Eq. (6) 


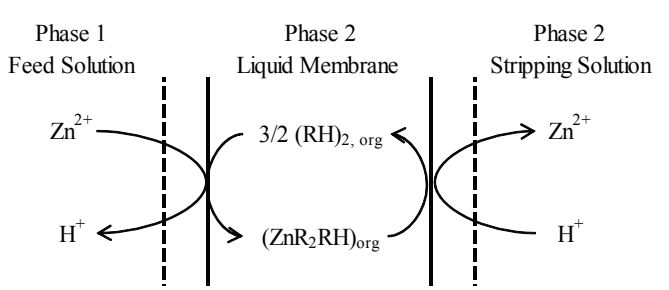

Figure 1 Transport scheme for extraction of zinc

$$
\begin{array}{cc}
-V_{f} \ln \left(\frac{C_{f}}{C_{f, 0}}\right)=A P \frac{\beta}{\beta+1} t \\
\text { by } \quad \beta=\frac{Q_{f}}{P L \varepsilon \pi N r_{i}}
\end{array}
$$

where $P=$ the permeability coefficient $(\mathrm{cm} / \mathrm{s})$

$V_{f}=$ the volume of the feed $\left(\mathrm{cm}^{3}\right)$

$C_{f, 0}=$ the zinc concentration $(\mathrm{mol} / \mathrm{L})$ in initial time $(t=0)$

$C_{f}=$ the zinc at time $\mathrm{t}(\mathrm{mol} / \mathrm{L})$

$A=$ the effective area of the hollow fiber $\left(\mathrm{cm}^{2}\right)$

$t=$ time $(\min )$

$Q_{f}=$ the volumetric flow rate of feed solution $\left(\mathrm{cm}^{3} / \mathrm{s}\right)$

$L=$ the length of the hollow fiber $(\mathrm{cm})$

$\varepsilon=$ the porosity of the hollow fiber (\%)

$N=$ number of hollow fibers in the module

$r_{i}=$ the internal radius of hollow fiber $(\mathrm{cm})$.

\subsection{EXPERIMENTAL}

\subsection{Chemical and Reagents}

The zinc phosphating rinsing water that is the feed solution from Thai NOK Co.,Ltd. The D2EHPA extractant was provided from Merck, Germany. The kerosene solvent was a commercial grade that provided from Shell. All reagent used in this experiment were of laboratory grade and provided from Merk, Germany.

\subsection{Apparatus}

A support material is the Liqui-Cel ${ }^{\circledR}$ ExtraFlow module which offered by CELGARD LLC
(Charlotte,NC; formerly Hoechest Celanese). The module uses Celgard ${ }^{\circledR}$ microporous polyethylene fibers woven into fabric and wrapped around a central tube feeder that supplier the shell-side fluid. The properties of a hollow fiber module are shown in Table 3.

Table 3 Physical characteristics of the hollow fiber module

\begin{tabular}{ll}
\hline Properties & Description \\
\hline Material & Polypropylene \\
Inside diameter of hollow fiber & $240 \mu \mathrm{m}$ \\
Outside diameter of hollow fiber & $300 \mu \mathrm{m}$ \\
Effective length of hollow fiber & $15 \mathrm{~cm}$. \\
Number of hollow fiber & 10,000 \\
Average pore size & $0.03 \mu \mathrm{m}$ \\
Porosity & $30 \%$ \\
Area per unit volume & $29.3 \mathrm{~cm} / \mathrm{cm}^{3}$ \\
Module diameter & $6.3 \mathrm{~cm}^{2}$ \\
Module length & $20.3 \mathrm{~cm}^{2}$ \\
Contact area & $1.39 \mathrm{~m}^{2}$ \\
\hline
\end{tabular}

\subsection{Procedures}

The single module operation system is composed of two gear pump, two variable speed controller, two rotameters and four pressure gauges as shown in Figure 2. At first, The liquid membrane was prepared by circulation of the extractant was diluted in kerosene into the tube and shell sides of the module for 50 minutes to ensure the extractant embedded in the micropores of hollow fiber. The feed solution was adjusted the $\mathrm{pH}$ value by $\mathrm{HNO}_{3}$ and $\mathrm{NaOH}$ until the $\mathrm{pH}$ of feed solution is 2.0-2.5 [9] due to Eq.(3) when were increased on $\mathrm{pH}$ is decreased protons. The reaction shifts forward more which follow on Le Chatelier's principle and stable on on $\mathrm{pH}$ more than 2.5 and the stripping solution was prepared by diluted $\mathrm{H}_{2} \mathrm{SO}_{4}$. Then, the experiment stared by pumped the feed solution into the tube side and the stripping solution was pumped into the shell side as counter-current flow and also the both sides are controlled flow rate as equal at $100 \mathrm{ml} /$ min that is the best contact time for metal ions to react [11]. The operation of each experiment was 50 minutes under room temperature $\left(30^{\circ} \mathrm{C}\right)$. The 


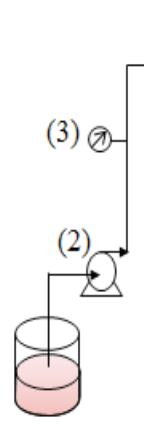

(1)

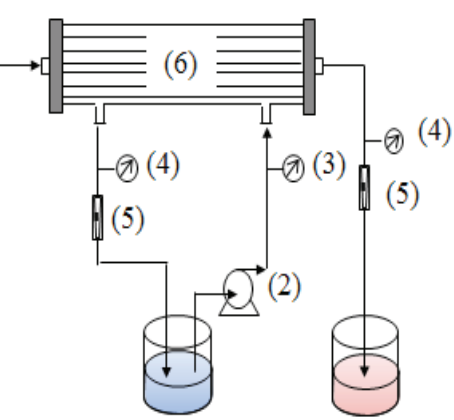

(7)

(1)

Figure 2 Schematic counter-current flow diagram for the recirculation mode operation in HFSLM: (1) feed reservoir, (2) gear pump, (3) inlet pressure gauges, (4) outlet pressure gauges, (5) outlet flow meter, (6) hollow fiber module, and (7) strip reservoir.

optimal condition used for continuous operation on 300 minute and control rate of chemical reaction by measuring $\mathrm{pH}$ value every 1 hour.

\subsection{Analytical Instrument}

Analyzing the amount of zinc were determined by using ax atomic absorption spectrophotometer (AAS), Varian model AA280FS.

\subsection{RESULTS AND DISCUSSION}

\subsection{The Influence of D2EHPA Concentration of the Membrane Phase}

Figure 3 shows the influence of carrier concentration between percentage of extraction. The percentage of zinc extraction was increased when the D2EHPA concentration was increased until highest percentage of extraction was $91 \%$ at $8 \%(\mathrm{v} / \mathrm{v})$ as the optimized concentration. Than percentage of zinc extraction was decreased when the D2EHPA concentration was increased because the viscosity of the membrane phase was increased which diffusion coefficient are reversely correlated with viscosity by Stokes and Einstein equation [12].

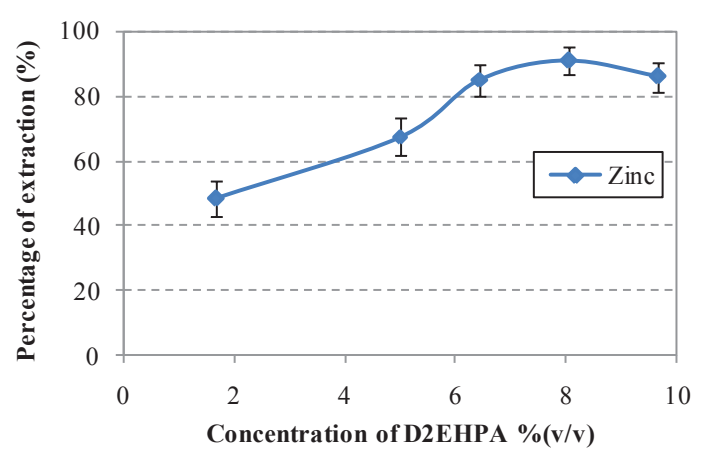

Figure 3 The percentage of extraction against the D2EHPA concentration: $\mathrm{pH}$ of feed solution $=2.5$, stripping concentration $=1.5 \mathrm{M}$ of $\mathrm{H}_{2} \mathrm{SO}_{4}$ and flow rate of feed and stripping solution $=100 \mathrm{ml} \mathrm{min}^{-1}$

\subsection{The Influence of Stripping Phase Concentration}

Figure 4 shows the influence of $\mathrm{H}_{2} \mathrm{SO}_{4}$ concentration. The highest stripping of zinc about $45.5 \%$ at $1.5 \mathrm{~mol} / \mathrm{L}$ of $\mathrm{H}_{2} \mathrm{SO}_{4}$ for 1 -cycle separation. At higher optimize concentration, the percentage of stripping of zinc was decreased which follow on Le Chatelier's principle.

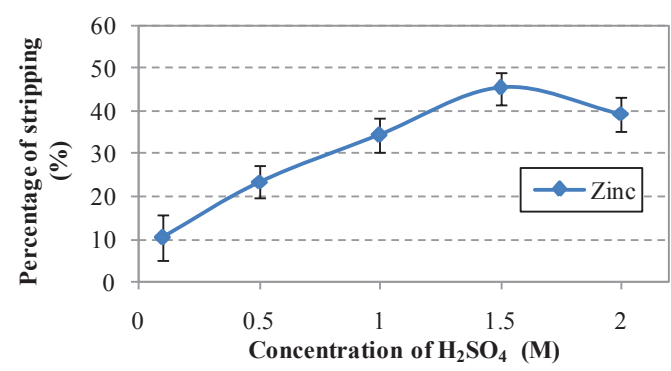

Figure 4 The percentage of extraction against $\mathrm{H}_{2} \mathrm{SO}_{4}$ concentration: D2EHPA concentration $=8 \%(\mathrm{v} / \mathrm{v}), \mathrm{pH}$ of feed solution $=2.5$ and flow rate of feed and stripping solution $=100 \mathrm{ml} \mathrm{min}^{-1}$

\subsection{The Extraction Equilibrium Constant $\left(K_{e x}\right)$ Distribution Ratio (D)}

Figure 5 shows plotting of $\left[\mathrm{Zn}^{2+}\right]\left[(\mathrm{RH})_{2}\right]^{3 / 2}$ versus $\left[\mathrm{ZnR}_{2} \mathrm{RH}\right]\left[\mathrm{H}^{+}\right]^{2}$ at equilibrium; the slope of the 
plot is the extraction equilibrium constant of zinc $\left(K_{e x}\right)$ as $2.450 \cdot 10^{-6} \mathrm{~mol}^{1 / 2} \mathrm{~L}^{-1 / 2}$ which estimated according to Eq.(4). The distribution ratio (D) at the D2EHPA concentration 1.5-8 \%(v/v) were calculated by Eq. (5) as shown in Table 4. It was noted that the distribution ratio increased with the extraction concentration increased; at above optimize concentration, the distribution ratio was decreased which agreed with the earlier report by Pancharoen et al. [13]

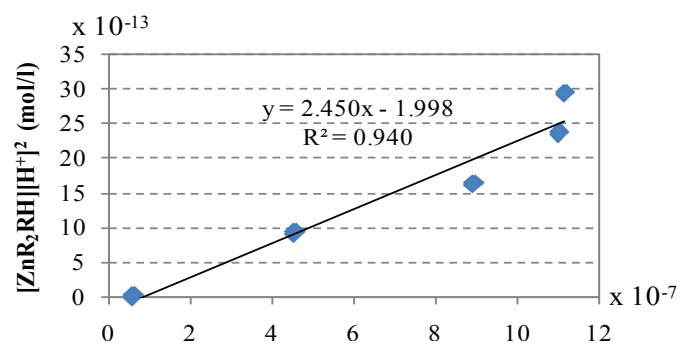

Figure 5 Zinc extraction with D2EHPA as a function of equilibrium $\left[\mathrm{ZnR}_{2} \mathrm{RH}\right]$ $\left[\mathrm{H}^{+}\right]^{2}$

\subsection{The Permeability Coefficient (P)}

Figure 6 shows the permeability coefficients for zinc separation as the function of D2EHPA concentration at $1.5-8.0 \% \mathrm{v} / \mathrm{v}$ follows Eq. (6) and (7). The results are shown in Table 4. The permeability coefficients increased with the extractantconcentration which are similar with

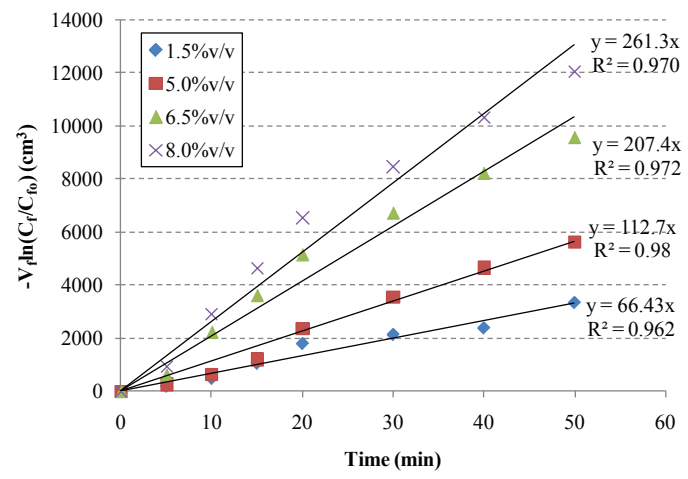

Figure 6 Plot of $-V_{f} \ln \left(C_{f} / C_{f 0}\right)$ of zinc ions in the feed solution against times, with different D2EHPA concentration
Table 4 The distribution ratio at the D2EHPA concentration of $1.5-8.0 \%(\mathrm{v} / \mathrm{v})$

\begin{tabular}{ccccc}
\hline $\begin{array}{c}\text { D2EHPA } \\
\%(\mathrm{v} / \mathrm{v})\end{array}$ & 1.5 & 5.0 & 6.5 & 8.0 \\
\hline $\mathrm{D}$ & 4.2 & 5.1 & 6.7 & 8.6 \\
$\mathrm{P} \cdot 10^{2}(\mathrm{~cm} / \mathrm{s})$ & 0.56 & 1.10 & 2.90 & 4.85 \\
\hline
\end{tabular}

distribution ratio coefficient values-agreed with the earlier report by Pancharoen et al. [13].

\subsection{The mass transfer coefficient ( $k_{i}$ and $\left.k_{m}\right)$}

The mass transfer through a hollow fiber liquid membrane are included diffusion 3 steps; The aqueous phase mass transfer coefficient in feed side $\left(k_{i}\right)$, the organic phase mass transfer coefficient $\left(k_{m}\right)$ and the aqueous phase mass transfer coefficient in stripping $\operatorname{side}\left(k_{s}\right)$. Assuming that the stripping solution reaction is instantaneous and contribution of the stripping phase is neglected and assuming that the flow through the tube side of a hollow fiber is laminar. Thus, $k_{i}$ and $k_{m}$ were calculated by SherwoodGraetzcorrelation [14]

$$
\begin{gathered}
G z=\frac{d^{2}{ }_{i} v}{L D_{a q}} \\
S h=m G z^{n} \\
S h=\frac{k_{i} d_{i}}{D_{a q}} \\
k_{m}=\frac{\varepsilon D_{m}}{\tau \eta \ln \left(\frac{r_{o}}{r_{i}}\right)}
\end{gathered}
$$

when $S h$ and $G z$ are Sherwood and Graetz numbers, respectively, $d_{i}$ is the inner diameter of fiber $(\mathrm{cm}), L$ is the length of fiber $(\mathrm{cm}), v$ is the linear velocity of the feed solution $(\mathrm{cm} / \mathrm{s})$, $D_{a q}$ is the diffusion coefficient of zinc in the aqueous phase which estimated by the WikeChang equation [15] as equal to $5.2 \times 10^{-9} \mathrm{~cm}^{2} / \mathrm{s}$, $m=1.62$ and $n=0.33$ follows theoretically for a diffusion process with fast chemical reaction which approximated by Leveque [16], $e$ is the 
porosity of a hollow fiber, $t$ is the tortuosity of a hollow fiber, $D_{m}$ is the diffusivity of zinc carrier complex in the membrane phase which estimated by the Wike-Chang equation [15] as equal to $1.4 \times 10^{-8} \mathrm{~cm}^{2} / \mathrm{s}$.

The estimation follows Eq.(8)-(11) and parameter as above of $k_{i}$ and $k_{m}$ values were $1.5 \times 10^{-5} \mathrm{~cm} / \mathrm{s}$ and $6.2 \times 10^{-7} \mathrm{~cm} / \mathrm{s}$, respectively. Thus, the rate controlling step of the diffusion of zinc ions across the membrane phase was organic phase mass transfer coefficient $\left(k_{m}\right)$.

\subsection{The Concentration of Stripping Solution After Continuous Operation}

The concentrate accumulation of zinc was separated through the hollow fiber liquid membrane into sulfuric acid solution as a stripping solution was studied by using the optimum condition in a single-module operation, operation 6 cycles and the concentration of sulfuric acid was adjusted every cycle. At the completely operation was found the maximum zinc accumulative concentration in stripping phase is $61 \%$ at 120 minute that means the durability of the system is 2 hour.

\subsection{CONCLUSION}

Progressive research helps waste water treatment from automotive industry. The optimum values of the parameters were applied to the phosphating rinsing water to attain high yields of zinc ions extraction and stripping. The best conditions were $8 \%(\mathrm{v} / \mathrm{v}) \mathrm{D} 2 \mathrm{EHPA}, 1.5 \mathrm{M}$ of stripping solution, Initial $\mathrm{pH}$ of feed solution of 2.5 and $100 \mathrm{ml} / \mathrm{min}$ of feed and stripping solution. The mass transfer coefficient of the aqueous phase $\left(k_{i}\right)$ and organic phase $\left(k_{m}\right)$ were $1.5 \times 10^{-5} \mathrm{~cm} / \mathrm{s}$ and $6.2 \times 10^{-7}$ $\mathrm{cm} / \mathrm{s}$, respectively. Therefore, the mass transfer controlling step is the zinc-D2EHPA through the organic phase.

The concentration of zinc ions remaining in the feed meets below limit by legislation, Thailand. Moreover, the byproduct from the process as the zinc sulphate solutions have high possibility to using in electroplating process as a raw material [17].

\section{REFERENCE}

[1] W.Mareta, H.H. Sandstead, 2006. Zinc requirements and the risk and benefits of zinc supplementation. Journal of Trace Elementin Medicine and Biology 20: 3-18.

[2] F.Fu, Q.Wang. 2011 Removal of heavy metal ions from wastewaters. Journal of Environmental Management 92: 407-418.

[3] W.Naito, M.Kamo, K.Tsushima, Y.Iwasaki. 2010. Exposure and risk assessment of zinc in Japanese surface waters. Science of the Total Environment 408: 4271-4284.

[4] N.Zheng, Q.Wang, D.Zheg. 2007. Health risk of $\mathrm{Hg}, \mathrm{Pb}, \mathrm{Cd}, \mathrm{Zn}$ and $\mathrm{Cu}$ to the inhabitants around Huludao Zinc Plant in China via consumption of vegetable. Science of the Total Environment 38: 8189.

[5] S.Micheal. 2008. Removal enrichment and recovery of $\mathrm{Ni}(\mathrm{II}), \mathrm{Zn}(\mathrm{II})$ from phosphation rinsing water with liquid-phase polymerbased retention technique. Separation and Purification Technology 63: 172-178.

[6] M.Kobya, E.Demirbas, A. Dedeli, M.T.Sensoy. 2010. Treatment of rinse water from zinc phosphate coating by batch and continuous electrocoagulation processes. Journal of Hazardous Material 173: 326334.

[7] D. He, X. Luo, C. Yang, M. Ma, Y. Wan. 2006. Study of transport and separation of $\mathrm{Zn}(\mathrm{II})$ by a combined supported liquid membrane/strip dispersion process containing D2EHPA in kerosene as the carrier. Desalination 194: 40-51.

[8] P. Ura, R. Prakorn. 2006. Feasibility study on the separation of uranium and thorium by a hollow fiber supported liquid membrane and mass transfer modeling. Journal of Industrial Engineering Chemical 12: 673681.

[9] A.Mellah, D.Benachour. 2006. The solvent of zinc and cadmium from phosphoric acid solution by di-2-ethyl hexyl phosphoric acid in kerosene diluents. Chemical Engineering and Processing 45: 684-690.

[10] P.R. Danesi. 1984. A Simplified model for the coupled transport of metal ions through 
hollow-fiber supported liquid membranes. Journal of Membrane Science 20: 231-248.

[11] P.Ramakul, E.Songkun, W.Pattaweekongka, M. Hronec, U.Pancharoen. 2006. Permeation study on the hollow fiber supported liquid membrane for the extraction of cobalts(II). Korean J. Chem. Eng. 23(1): 117-123.

[12] D.Buachuang, P.Ramakul, N. Leepipatpiboon, P.Ura. 2011. Mass transfer modeling on the separation of tantalum and niobium from dilute hydrofluoric media through a hollow fiber supported liquid membrane. Journal of Alloys and Compounds 509: 9549-9557.

[13] U.Pancharoen, S.Somboonpanya, S.Chaturabul,A.Lothongkum. 2010. Selective removal of mercury as $\mathrm{HgCl}$ from natural gas well produced water by TOA via HFSLM. Journal of alloys and compounds 489: 72-79.
[14] N.M. Kocherginsky,Q. Yang, L. Seelam. 2007. A Recent advances in supported liquid membrane technology. Separation and Purification Technology 53: 171-177.

[15] N.M. Kocherginsky, Q. Yang. 2007. Big Carrousel mechanism of copper removal from ammoniacal wastewater through supported liquid membrane. Separation and Purification Technology 54: 104-116.

[16] G.R.M. Breembroek, A. van Straalen, G.J. Witkamp, G.M. van, Rosmalen. 1998. Extraction of cadmium and copper using hollow fiber supported liquid membranes. Journal of Membrane Science 146: 185195.

[17] M. Mortaga, Abou-Krisha. 2005. Electrochemical studies of zinc-nickel codeposition in sulphate bath. Applied Surface Science 252: 1035-1048. 
